\title{
ALTERNATIVE STRATEGIES IN INTERNATIONAL MARKETING
}

\author{
Gökhan YOLAÇ \\ Beykent University, Lecturer, Dr.
}

\section{ALTERNATIVE STRATEGIES IN INTERNATIONAL MARKETING}

\begin{abstract}
In today's world where globalization has an ever increasing effect on the world economy, where the competition becomes more ruthless in time, the technology is changing at a faster pace, and with the increase in the importance of the international markets, the companies' activities are increasing their activities in this field. International markets and international marketing is becoming more important for companies, and they no longer settle only for their domestic markets but are also gravitating towards foreign markets. A great increase in the number of companies showing global activity especially after 1990s is observed, the globalization process becomes more pronounced. The marketing strategies that can be implemented in international markets attain great importance within this framework. While marketing might have been unknown pre-rineties, it has now become essential for the survival of a business. $A$ business which does not compete in international markets in today's world be faced with the prospect of not being able to compete in its domestic market with its international competitors who have lower costs, much more experience and a wide product range. Within this context, in this study we will discuss in depth the standardization and adaptation strategies along with a mixed strategy and look at different aspects of each.
\end{abstract}

\begin{tabular}{llll} 
Keywords: & $\begin{array}{l}\text { International } \\
\text { Standardization. }\end{array}$ & Marketing, Adaptation, \\
\hline
\end{tabular}

\section{INTRODUCTION}

The first developments regarding the standardization and adaptation strategies have started at the end of $1960 \mathrm{~s}$. The first few articles that have also become classics on this subject were published in years 1968 and 1969 and later in 1970s other important publications followed these; and in 1983 the pioneering and very famous article in its subject "Globalization of the Markets" was published.

The first advancements in standardization and adaptation strategies, which have an important place in international marketing, were first seen in the late 1960s. The first few articles that were published and became classics in their fields in the years 1968 and 1969 were followed by a few important articles published in 1970s, which was then followed by the famous article "the

\section{ULUSLARARASI PAZARLAMADA ALTERNATIF STRATEJILER}

Özet: Küreselleşme olgusunun her geçen gün biraz daha dünya ekonomisine damgastnt vurduğu, rekabetin acımastz bir biçimde arttı̆̆l, teknolojinin huzla değiștiği günümüzde, uluslar arası pazarların öneminin gitgide artmastyla ișletmelerin bu alanlardaki faaliyetleri de hizla artmaktadır. İsletmeler için uluslararasi pazarlar ve uluslararast pazarlama gitgide daha fazla önem kazanmakta, işletmeler artık sadece iç pazarla yetinmeyip dış pazarlara da yönelmektedir. Özellikle 1990'lardan sonra küresel pazarlarda faaliyette bulunan işletmelerin saytsinda büyük artıslar gözlenmekte, küreselleşme süreci daha çarpıct bir biçimde kendini göstermektedir. Uluslararast pazarlarda izlenebilecek pazarlama stratejileri de bu çerçevede büyük önem kazanmaktadir. Pazarlama 1990'lar öncesi kavram olarak bile bilinmezken, artık bir işletmenin varlı̆ğm sürdürmesi için zorunlu hale gelmektedir. Günümüzde uluslar arast pazarlarda faaliyette bulunamayan bir işletme, daha düşïk maliyetlerle, daha büyïk is tecrübesiyle ve daha çok mamul cessidiyle karşısına çkan uluslar arası rakipleriyle kendi ülkesinin pazarında bile rekabet edememe tehlikesiyle karşı karşıy6a kalabilmektedir. Bu bağlamda, bu çalışmada uluslar arast pazarlamada standardizasyon ve adaptasyon stratejileri ile karma strateji ele altnarak çeşitli boyutlartyla incelenecektir.

Anahtar Kelimeler: Uluslararast Pazarlama, Adaptasyon, Standardizasyon

globalization of the markets" published in 1983 which is regarded as the pioneer work on the subject of globalization.

\section{VIEWS ON THE STANDARDIZATION AND

$\begin{array}{lcc}\text { ADAPTATION } & \text { STRATEGIES } & \text { OF } \\ \text { INTERNATIONAL } & \text { MARKETING } & \text { IN } \\ \text { PRESENT TIMES } & & \end{array}$

Following Theodore Levitt's famous article that became the cornerstone in the field of globalization since it publication in 1983, intensive research and discussions started in this field. In this study, views defending the standardization and adaptation in international marketing in the light of Levitt's article shall be first taken into consideration followed by global thought and global strategy and local application approaches in this context. 
Morever, global markets offer unlimited opportunities. To be globally successful, companies must learn to operate and compete as if the world were one large market, ignoring soperficial regional and national differences. Basic forces such as; growing similarity of countries, falling tariff barriers and strategic role of technology have led to globalization of markets [1].

\section{II.1. The Opinions Defending Standardization Strategies in International Marketing Mix}

The introduction of products to international markets in a standard form and under a standard brand constitutes the fundamental principle of global companies and globalization. The advantages that are obtained through this approach demonstrate the superiority for which standardization should be preferred. Standardization can be approached in two ways. These are:

- The standardization of marketing programs.

- The standardization of marketing processes [1].

While the marketing programs take the different aspects of marketing mix into consideration, the marketing processes refer to the assisting material used in the application and development of these programs. The factors, which affect the standardization of marketing programs on a conceptual level, are: the target markets, market position, quality of the product, environmental and organizational factors. These factors, on a standalone basis or together affect standardization in different ways and in different decision platforms. Naturally, the geographical region it is situated in and various economic factors influence the target market. When global consumers are taken into consideration instead of countries, the application of standardization is easier in countries that have similarities. Where the product is on its product cycle, cultural and economic disparities, the differences in perception of consumers and competition, all have an influence on standardization. As the resemblance in consumer behavior and life styles in the market increases, the applicability of standardization level increases in the international marketing mix. This is because it becomes easier to apply standardization strategies in societies where the cultural values concur. Furthermore, as the level of similarity in competitive condition increases, the standardization level increases as well. The fact that the product is and will be positioned for industrial or for consumer consumption are concepts that are very closely related to the product's quality. Industrial and high technology products are more appropriate for standardization when compared to consumer products. If the domestic positioning strategy can also be applied in other countries, than there exists a better circumstance for standardization. Basically the product mix elements are the same elements for domestic and international. However, the variations stem from environmental factors. Physical, economic, politicallegislative infrastructure related to marketing are the main factors that define this difference. As the differences between the above mentioned factors increase, the degree of standardization decreases. In spite of this, the standardization degree between countries increases in countries, which have similar marketing infrastructures. If the headquarters and the reporting organizations of multinationals can have a consensus on important strategic decisions, than the standardization strategy is being implemented successfully. As centralization increases in the matter of policy formation and resource allocation, standardization also increases. Success in standardization is dependent on the success of economic performance. The factors that would bring about this success are, obtaining competitive advantage, and benefiting from economies of scale [2].

The businesses acquire major advantages with the selection of standardization strategy and the increase in the level of standardization [3]. The most important advantage achieved by standardization is the benefits of the sizeable savings achieved from economies of scale. This is especially true in instances where production is done at one location, and then major gains are achieved; however if it is performed in several locations worldwide, then this advantage diminishes. If a firm introduces the same product globally, than it will achieve better results from its Research \& Development, it will provide savings and the probability of its success will increase. The fact that there will be less research done for the specific demands of national markets will make it easier to allocate more resources for new products. Standardization provides advantages in product development costs in the same manner. Although sales force training, advertisements and similar activities may show slight differences between countries, in cases where the product is standardized, it can show far more similarities than when the product is adapted.

The standard product marketing will bring major benefits in after sales services, spare parts procurement, stock control and similar matters just like the large-scale production does. Furthermore, the promotional activities carried out in the same language throughout different markets - especially in advertisements - have additional yields. Standard product increases product and brand loyalty in consumers who travel frequently, as such, the consumer can find and purchase the products wherever he/she travels to. In certain countries, the country of origin gives a product in certain product categories an advantage. These advantages can be identified in American chewing gum, Coca-Cola, French perfumes or women's wear, Japanese electronic equipment or compact cars. If the firm can only access foreign markets through exports, than it will be easier to export the standard product. The exporting firm usually prefers markets 
where no adaptation or very little adaptation is required. This is because global penetration into new markets can be performed very quickly with a standard new product, and can achieve important advantages in relation to international markets for its promotional activities in branding, labeling and guarantee policies [4]. The cost of new product or the cost of new product development has a high turnover rate due to the marketing on a global scale. This feature allows the depreciation of costs in a shorter timeframe. Another important benefit of standardization is the fact that it decreases the cost of stock. As it becomes possible to hold a minimum level of stock for standard products, the cost of stock naturally decline [5].

The continuity of the firms and the quality image of the product can be better obtained with standardization. For example, McDonald's owes its worldwide success to the continuity and reliability of its product and service quality. The minced meat, burger buns, French fries it uses have special qualities, and just because there are no potatoes grown in Europe providing the required qualifications, the company imports potatoes into this continent from other countries. McDonald's does not make any concessions from quality; it even shut down a McDonald's fast-food outlet, following complaints made by a group of Parisian consumers in 1982. This was because the owner of the establishment did not comply with the mandatory and required quality conditions set forth by the franchising licence agreement.

Some products are hard to change or revise due to their nature, musical works and other art works can be shown as examples to this. Besides differentiating these according to different markets is difficult, it is also difficult to forecast which will be successful in which markets. Different consumers from different countries may need the same products for their similar needs.

\section{II.2. Opinions Defending Adaptation in International Marketing Mix}

Opinions defending adaptation in international marketing mix depend on the premise that the firm will fundamentally have higher revenues through adaptation. According to these views, adapting the product according to the demands and needs, is more effective than lowering the costs by way of standardizing. This is because the adapted product, which better conforms to consumer demands, will sell more, resulting in higher sales revenues and profits. Specific factors besides this general opinion play an important role in the selection of adaptation [3]. Although it satisfies similar needs in different countries, the operating conditions change from country to country. For example, since factors such as climate, heat, humidity affect the operating conditions greatly, adaptation becomes a necessity in such circumstances. Oil prospecting in the desert is undertaken in totally different climate and geographic circumstances to that of oil prospecting in Alaska. The level of development between the countries is another important point requiring adaptation. The dissimilarities between road and traffic conditions in various countries require the adaptation of vehicles like cars, trucks, as well as their complementary products like tires. In a parallel format to this, the habits and value judgements of the inhabitants of the country make adaptation necessary. For example, while there is a hot water pipe and cold water pipe connections to washing machines in some European countries, in others there is only one cold water pipe connection and the machine heats its own water. The distribution of per capita income, which is an important indicator of purchasing power, shows great discrepancy between countries. This situation results in the differentiation of country markets. While per capita income in some countries is in the range of $\$ 25,000$ to 30,000 , it is less than $\$ 300$ in some others. This vast difference in income, besides affecting the quality of products, also affects pricing and packaging. Worldwide consumer preferences are far from having similar characteristics. Different preferences are encountered from market to market and between countries. These different preferences may take place even between neighboring countries. For example, while the French prefer four door cars, the Germans prefer two door models [3].

Product adaptation may sometimes be required due to legislation in the domestic markets. In certain Islamic countries like Saudi Arabia, sale of alcoholic beverages is forbidden and beer that only contains $0.5 \%$ alcohol which is considered as non-alcoholic in the western world is also forbidden, and non-alcoholic beer is produced following special procedures.

Some governments may demand that instead of being imported, some products should be produced domestically. These prohibitions and limitations that are set, makes it mandatory for the products to be adapted and produced in the country. Another tool that is used as an incentive and coercion in local production is taxation. The tax concessions provided as an incentive are a major impulsive force for domestic production. Furthermore, the limitations and the arrangements of governments play an important role in the packaging, labeling and the attributes of the products. As an example, the Italian government only allows the production of spaghetti from a special type of wheat called "durum" [3].

Influenced by the nationalistic trends prior to World War II, instead of producing in other countries, firms did their productions in their domestic markets, and afterwards they adapted and introduced these to international markets. The most important thing that effect standardization in our day is the converging of tastes at the same common points, and the increase in the similarities of consumer preferences. The decrease in differences of consumer preferences significantly 
encourages standardization. However against all this similarity and convergence, product adaptation has become inevitable. For example, Hoover Company has identified some interesting differences in the research it did on the subject of washing machines in several countries [3]. According to this research; the consumers in France, Italy, Germany and Sweden prefer machines with different dimensions, made from different materials, that have different functions. While the French, Italian and British prefer narrow machines; Germans and Swedish prefer wider machines. While the British prefer top loading machines, the others prefer front-loading machines. At the same time, the washing capacity of the machines and dryer speeds change between countries.

From a different perspective, according to the same research, the British and the Swedish do not want the machine to heat the water. This is because in these countries hot water comes from the central systems. On the other hand Italians, Germans and French want the system which will heat the water in the machine. In a similar manner preferences for the appearance and drying systems of the machines are different in each country. While appearance is not important for the British, Italians prefer bright coloured appearances, French prefer elegant appearance, Germans prefer reliable looking, and Swedish like machines with a powerful look.

Globalization tendency in international marketing and standardization policies related to this; depends on the assumption that the differences between consumer needs, demands, and tastes are decreasing and homogenizing. Now, there is global competition between firms. Globalization is taking its place in firm policies, centralization tendencies are observed in these policies [6]. Unlike these assumptions, consumption is very closely related to culture and lifestyle. This relation is especially strong in consumer goods. As an example, Carlsberg has added one more elephant to the two elephants on the labels of the product it sells in Africa. Because two elephants are regarded as symbol of ill omen in Africa. Empirical research has shown that culture is a barrier to entering a market in perishable consumer products. Besides this, language stands out as a very strong other barrier that establishes the cultural borders.

The great economic differences between countries, the different purchasing power, cultural and psychological differences require modified marketing strategies and applications in various countries.

The strategic management should be local; however it is necessary to have the marketing management adapted according to the domestic needs and demands. This is realized through the convenience that global marketing provides to the congruity of various cultures in international marketing [6].
Another situation that requires product adaptation is the frictions that arise between company headquarters and related establishments or between the company headquarters and local distributors in multinational companies [7]. The local management wants to diminish the power of company headquarters and take on the implementation of strategic decisions. The management of related local establishments that are far from the headquarters becomes difficult and there are several difficulties that arise related to these. On the other hand, the managers of distribution channels and related establishments, believe that since they are close to the market and know the local market conditions and consumer needs better, they could provide a better service. There are many factors that become the cause of friction between local managers and headquarters. According to this view, cost savings are not only achieved through economies of scale. There are "hidden costs" that arise from the frictions between the headquarters and local establishments or representatives and distributors.

\section{II.3. Mixed Approach: Think Global, Act Local}

Globalization reflects a business orientation based on the belief that the world is becoming more homogeneous. So companies need to globalize their international marketing strategy [8].

In today's world where global competition has increased, international market segmentation strategy is unavoidable for global firms. It is possible to take advantage of both the adaptation and standardization strategies in this way. In the market segments that show similar characteristics, the marketing efforts are standardized, whereas in the market segments that show different characteristics the marketing efforts are differentiated and adapted. For example, companies such as Benetton, Levi-Strauss, Swatch International have chosen and are targeting the "youth" market segment worldwide as their target market. Success has been achieved in satisfying the lifestyle values of such a "global consumer segment" [9].

Global strategy, is based on determining market opportunities, threats, risks and resources in business activities on a global scale. In such a strategy formed for success on a global scale, discipline, creativity and continuous effort are required. As a result, not only success is achieved but also the firms are able to sustain their existence in this way [10]. The firms need to have five fundamental qualities to develop global strategies [11]: To have a worldwide market share, to be able to adapt the product for different countries according to their preferences without changing its essential quality, the concentration of value added activities in a few countries, adaptation of single type market positioning and marketing mix, to have an integral competitive strategy between the countries. The benefits these qualities 
provide may be summarized as below:

- Having a big market share worldwide makes it easier to depreciate investments and simplifies managing different countries as if managing a single portfolio. Having activities in many countries means accumulating different experiences from different countries.

- In the global strategy, the essence or the fundamental characteristic of the product does not change, it is adapted to the consumer preferences of different countries. For example McDonalds applies this strategy very succesfully. This company makes the necessary changes to its products in Europe, Japan and America according to local tastes. But the implementation of this adaptation inline with many countries results in the diminishing profits from the economies of scale potential.

- Realizing some of the activities that create added value in a small number of countries increases the benefits achieved. For example, Research \& Development are performed in one country instead of being repeated in all countries. Following this, the production of the product is done in a small number of countries; the basic marketing programs are developed in the regional centres; sales and consumer services are performed in all countries. As such, special expertise and manpower of certain countries are utilized. As a matter of fact specialization and cheap labour seem to be the foremost reasons the production of electronic equipment on a global scale is carried out in countries like Hong Kong and Malaysia.

Single type positioning and single marketing mix formation provides savings in the marketing strategy and program development costs.

Instead of going through market share battles in one or a few countries, the firms, which have a global strategy, have an integral approach. Therefore instead of focusing on one market they look at the world markets from a global point of view. Another important benefit of this approach is, it provides the opportunity to invest in markets with strategic importance which have a low market share, with the revenues gained from profitable, high market share countries. As such a worldwide optimization will be established [11].

\section{II.3.1. Factors Affecting Global Strategy Selection}

Prior to selecting its global strategy, the firm should evaluate its industrial potential. The main factors that affect global industrial potential may be taken into consideration under main groups as, factors forming the market, environmental factors, economic, competitive and organizational factors [11].
- Factors Forming the Market. Are those market factors affecting the consumer's acceptance of the global product, homogenized needs in the markets, shortening of the product's life cycle, globalization of the consumers, ability to transfer brand and advertisement and internationalization of the distribution channels.

- Environmental Factors. These are lower transportation costs, developing communications, change in technologies and governmental policies.

- Economic Factors. Benefiting from economies of scale in distribution and production, learning curve effect, major cost differences between countries can be counted as economic factors.

- Competitive Factors. Active global participation of competitors and interdependence of countries arising from competition can be determined as the main competitive factors.

- Organizational Factors. Organizational factors can play either a supportive or an obstructive role in determining the global strategy decisions of the firms. The potential of the organization plays an effective role in the subject of globalization. Organizational structure, management processes, people and culture are the main factors, which affect the potential of organizations in global strategy development and implementation [11].

One of the most effective ways of developing and implementing global strategy is to assemble all authority concerning the organization structure at headquarters. The separation of the organization as local and international, constitutes the much known structural obstruction to global strategy. The affiliates of an international firm take on an independent (autonomous) structure in their own countries. One of the duties of top management is to ensure coordination between the firm and its affiliates. Management processes become effective in global planning, budgeting, performance, global strategy development and implementation. Having multicultural people form different countries with different background and experiences, play an important role in the globalization of the firms. Furthermore, culture that is the most complex aspect of organizations may play an obstructive or supportive role in the realization of global strategies.

Both adaptation and standardization strategies may be accepted and benefited from once similar markets and markets with differences are identified [9]. The main challenge is to be able to form effective strategies for similar consumers beyond the national borders. Nonetheless, there are many factors that need to be taken into consideration in the development and implementation of appropriate strategies for the countries. There are also 
many restrictive factors in strategy selection. When the marketing mix components are examined one by one, it will become evident that each one has a different effect on the standardization strategy.

Several factors as diverse as the product, price, promotion and distribution, which make up the marketing mix components, effect the selection of the strategies and international market segments to be followed.

It is possible to group these effects with each component separately and review them as provided below [9].

\section{II.3.1.1 The Product Related Factors Affecting the Selection of a Global Strategy}

- Compared to the consumer products, Industrial products are more appropriate for standardization. Perishable consumer goods may need more adaptation in comparison to the durable consumer goods.

- The culture related products need more adaptation in comparison to the products that have no connection with culture.

- It is possible to highly standardize the marketing strategy for basic commodities.

- High degree of adaptation is required in the markets where competition is strong.

- High degree of adaptation is a requirement for substitute goods.

- It may prove to be difficult to standardize the marketing strategies for products going through different phases of their life cycles in different markets.

- The marketing strategy for new products must be adapted for them to be successful in the market place.

- The different ways of utilization in different markets may require high degree of adaptation.

- Even under the same conditions of utilization, the products in different markets with different functions that meet different needs will necessitate adaptation.

- In consumer markets that view various specifications of the product as important, adaptation will be a necessity.

- When its country of origin defines the attitude towards a foreign made product, then there will be a need for adaptation.
- When the standards, specifications, safety measures related with a product are based on the legislation in application then there will be a need for adaptation.

- There is a need for an adaptation strategy to overcome the difficulties related with the differences in language.

\section{II.3.1.2 Price Related Factors Affecting the Selection of a Global Strategy}

- The differences in the markets with respect to the costs of Research \& Development, production and marketing increase the need for adaptation for that product.

- The degree and intensity of competition in the industry effects the degree of price standardization.

- The price elasticity of an internationally marketed product at different stages of its life cycle will have an effect on the need for standardization.

- The differences in economic levels and consumers' understandings in different countries makes single price application over different markets difficult.

- The price elasticity of demand shows differences according to the type of the consumer. This situation makes single price application difficult to implement.

- In a market under the control of buyer's monopoly due to the fact that the buyer instead of the seller determines the price, some limitations will be placed on the standardization of price strategy.

- The fluctuations in the foreign currency prices due to the risks involved will have an effect on the pricing decisions.

- The legislation put into effect and the arrangements made by the governments show differences from country to country. Under these conditions it would be harder to standardize the pricing applications.

- The structure of the distribution channels will effect the standardization strategies.

- Furthermore, the competitors and the markets that these competitors are in interaction with, shall also have an effect on the pricing decisions of the firms. 


\section{II.3.1.3 Promotion Related Factors Affecting the Selection of a Global Strategy}

- Promotion strategy with respect to the words, terms, slogans, symbols and colors used in the advertisements broadcast in different countries must be adapted.

- Promotion strategies must be adapted so that they do not cause unwanted reactions in different cultures and values.

- The ways of utilization of media and promotion messages published in societies where level of education and reading and writing shows differences among the consumers must be adapted.

- When there is a negative attitude towards foreign based campaigns, promotion messages must be adapted.

- The culture and the habits can make one type of communication more acceptable and this situation may affect the standardization.

- The limitations placed by the governments may affect the level of standardization that may be implemented.

- The differences in the budgets allocated to different countries by the companies may cause the level of standardization to be lowered.

\section{II.3.1.4 Distribution Related Factors Affecting the Selection of a Global Strategy}

- The complexity, effectiveness and presence of the distribution channels will effect the standardization strategy to be applied with respect to these channels.

- Also the decisions and the arrangements of the governments will have an effect on the standardization strategies in this area.

- The geographical structure and the geographic distribution of the markets effect the choices made with respect to the distribution channels, and this effect shall be reflected in the standardization of the strategies.

- The competition in the channels of distribution in different countries shall effect the degree of standardization.

- The nature of the product plays an important role in the determination of the distribution channels, and this situation in return effects the standardization strategy of the distribution channels.
- The cultural values, purchasing habits, stocking policies increases the need for an adaptation strategy in the distribution channels.

The companies emphasize their national identity by giving priority to the workers from their own country. For example, most American firms have a tendency to employ workers from their own country even if the cost of labour in foreign countries is cheaper. This situation however causes disadvantages with respect to costs in a competitive environment. Similarly, the high level of requests made for autonomy by the domestic establishments presents obstacles on the way to globalization. It is difficult to think and compete on global terms. It is required for the top management to have a long-term viewpoint for global competition. With this kind of a viewpoint and way of thinking the competitive advantage can be achieved in costs and the needs and desires of the consumers can be met in a better way. In today's world international competition in several industries is very different from what it was in the past. The global firms while increasing their competitive force from one side are reducing the competitiveness of their competitors. Several companies due to their nature stay domestic bound in terms of business. The reasons for this phenomenon are the cost of transportation and insufficient economies of scale [12].

The first criteria for global competitiveness are whether the industry in which the company is active has the potential for global competition or not. There will be visible gains in cases where the benefits derived from being superior in competition or providing services are more valuable than the extra costs that will be incurred by being active in the global markets.

Determining the level of potential for the economies of scale depends on research. The advantages of an increase in the volume of production can originate from logistics and high volume distribution channels along with large-scale production. Furthermore, a world wide production volume supports high level of investments in research and development. Also the effects transportation costs on globalization are more pronounced in some sectors compared to the others. As an example this effect is less in optical products but more in iron and steel. Several establishments cannot participate in global competition due to insufficient economies of scale, low spending on Research \& Development, inter-country product differences, distribution and other related obstacles (governments, transportation costs). It has been witnessed that some global companies have become successful without even realizing their potential to become global. Although there are no guaranties for a company to become global, it should be willing to take the risks in making the heavy investments that are required to become globally competitive. After a company realizes its potential for becoming global, it 
should understand the affects this will have on competition and should choose to develop this potential in an effective way. To accomplish the said, the company should find the best answers to the following three questions [12].

- What kind of a technological innovation can start the global competition?

- Is the company in the best possible position among its competitors to form and maintain the advantages of global competition?

- For a leading position what kind of resources are needed and for how long?

The competition must be perceived in a global sense and the corporate strategy must be formed on a worldwide scale. In this subject, companies like American Caterpillar, European Ericsson and Japanese Honda can be mentioned as examples. These companies changed the rules of the game called competition in their certain industries by way of strategic innovations and acted in a bolder and more effective way compared to their competitors. They form preventive measures that are prepared with care against the reactions of their competitors. Caterpillar has developed a unique global strategy and chose to take advantage of economies of scale to its fullest extent with the investments made in the manufacturing industry. It also reinforced the said policy with the worldwide sales achieved. Furthermore in 1963 it entered into a joint venture together with Mitsubishi, a weak competitor of Komatsu, and blocked Komatsu's way in the Japanese market and took that company under its control. Ericsson is a good example of a small company becoming global by adopting a global strategy. This company was successful in turning a business of small telephone systems into a business of electronic systems and preventing the entry of other companies into the market.

Honda that constitutes the third example has chosen American middle class consumers as its target group and helped its customers to adopt the view that motorcycles can be tools of entertainment with the models that are not expensive. To the new consumers, by way of intensive advertising, trade exhibitions and displays, it has promoted the idea that motorcycles are inexpensive and that they are reliable and easy to use; and later on through wide distribution network, guaranties, spare parts and service network reinforced this opinion. In time nearly half of the motorcycle owners purchased more expensive and heavier models. In this process the trust and loyalty in the trademark played a significant role. After this, Honda, by taking advantage of the production based on economies of scale achieved great savings. The bottom line was, Honda reported large profits due to the savings achieved in production, distribution, marketing and costs of production and with the driving force gained from this success the company was able to direct its efforts to the car industry. All of the three companies mentioned above were not satisfied with a product that is addressing the interests of the worldwide markets but also took into consideration the local differences, although doing so was costly [12].

Timing is important in global success and it is also important to utilize the advantages of production and distribution before the competitors. Furthermore realizing the basic investments ahead of time will bring an added advantage.

In global competition, the advantage over the competitors can be achieved by product diversification and establishment of a strong worldwide distribution network instead of focusing on a standard product [13]. A worldwide production if not supported by a global distribution system may pose great risks; cost advantages are less stable than the advantages associated with trademarks and distribution. The objectives of a multinational company can be classified under three categories. These are; ensuring effectiveness in the present activities, management of risks that might be faced as a result of these activities, improving the learning capacity so that innovations can be made and that adaptation to the changes in the future can be achieved. A successful strategy involves handling and management of these different objectives together, in a way that is associated with each other [14]. By optimizing, this set objectives that are different from and in conflict with each other the company can take decisions that will ensure its competitive advantage over others. The tools that are in possession of the company for establishing its competitive advantage, and achieving and accomplishing the aforementioned objectives are as follows; taking advantage of input-output markets in different countries, benefiting from economies of scale in various activities, and realizing the benefits of synergy created by different activities or large scale operations. The companies try to achieve a return by maximizing the effectiveness with the resources that they already have. In these activities they might be exposed to various risks. These risks can be examined under the following headings [14].

- Macroeconomic Risks. These are the risks that are completely out of control. Wars, catastrophes, foreign exchange rates, interest rates are a few examples of the risks that can be examined under this group.

- Political Risks. These usually develop in connection with the macroeconomic risks, like implementations of the government. However one significant feature of these risks is that they can be controlled to a certain extent.

- Competitive Risks. These risks develop as the 
other companies in the market do not show any reaction to the strategic decisions of the company or if they maintain their ambiguous stance. Furthermore, there is a technologic risk associated with the utilization of the new technologies by the competitors.

- Resource Risks. These risks develop when the company does not have the sufficient resources or cannot allocate the resources for the strategies that it wants to implement. The risks due to resources can stem from lack of good management, or insufficient technological means and capital.

Multinational companies can make higher profits by taking advantage of different trademarks, technologies, and distinct management styles in different countries. By being operational in different countries the capacity for learning increases and hence the opportunities to make higher profits. The global competitive advantage can be established by utilizing various tools. By taking into consideration the resources and the concentration of the factors specific to the countries and by taking advantage of these, competitive advantage can be achieved. Scale economies have strong theoretical foundation. A Company must increase its production to the point where benefits from economies of scales are realized. Otherwise the competitor companies shall fill in the space left over. On the other hand, it should be taken into consideration that manufacturing two or more different products together is less costly than producing them separately. With a global strategy, the company can transfer the factors that create value to different countries in the most effective way possible. Later these units shall be integrated and managed in connection with each other. Although today's competitive environment makes up a global horizon, what managers know best is what they see best; and this is the customer that is most geographically close to them. Most of the managers see what is close to them and have short-term vision. This short-term thinking is not intentional. But still very few managers consciously develop plans and establish organizations with a view that includes all the important customers located at the same distance from the company head quarters [15].

Effective global studies need a realistic equal distance approach. However even with the most optimistic outlook, the managers find it difficult to develop and maintain such a viewpoint. To give you an example; the president of a Japanese corporation cancelled most of his important business meetings to be present at the funeral of one of his local salesman, however when the same president was asked whether he would do the same thing for a Belgian salesperson that every year realizes higher volumes of sales in comparison to his Japanese colleagues, the Japanese President's answer was a definite "no". The most they would do was to appoint a manager responsible of European affairs to send letters of condolences. This manager by acting against the equal distance principle discriminated among the salespeople. The said manager sent wrong signals and reinforced wrong values. These are the results of narrow points of view. The first rule of equal distance is to prioritize visualizing and thinking on a worldwide scale. On a map the borders between the countries are clear. But when the financial and economic activities based on competition is the subject matter these borders are mostly lifted off. What removes these borders is the continuous and fast paced information flow, that was at the beginning monopolized by the states in ways and forms that were created and deemed appropriate by them. The information monopoly that was established by the states with respect to the information pertaining to what is happening in the world gave them the authority to mislead and control the people. The reason for this was that they were the controllers of the actual facts in any such event. However in today's world people can obtain information from any corner of the world that they wish. Now people are informed about the tastes and preferences of the people living in other countries and they can see their life styles and the fashion they follow. Through information flow the people are becoming global customers and they want to buy the best at the cheapest price available regardless of the country of production. Parallel to this trend the companies are also becoming global in similar ways. Universal flow of information carries high importance for the managers in learning ways of developing a strategy and an organization that is appropriate to meet the needs of a world without borders.

To work globally, it is required to think and act globally. The customers form the only reasonable cause for thinking globally. Today, the companies are faced with the following important issues; effectively competing in the world markets and developing a global marketing strategy. The long term dynamic strategies of the companies must have a worldwide stable competitive advantage. This kind of strategy must at the same time be compatible with participating and fast changing markets. But, the global strategies that are developed by the companies can be different. This at the same time depends on the levels of participation in the international markets that the companies are displaying. During first entry stage to the international markets, the markets having the highest number of the most attractive opportunities are preferred; the companies try to gain advantage in these markets. After the company is successful in the international markets, it tries to expand its product line, develop new products, and establish new marketing tactics to effectively carry on its marketing activities in the local markets. Later on the pressure will build up for increasing the global effectiveness, coordination and control along with the transfer of information within the company. A global strategy will be developed to derive opportunities from global synergy potential and competition [16]. 
Global markets have differences with respect to their history, resources, capacities, and competitive power. In the past most of the discussions on global strategies were about the multinational corporations from Japan, Europe and United States. These corporations, after achieving a certain level of competitive power in the foreign markets, marketed their products to underdeveloped countries and obtained a worldwide controlling position. However, nowadays these markets are taken hold of by the small and medium scale establishments from the developing countries. At the same time many of the public institutions that are state monopolies are being privatized and take their places in competitive arena. To be effectively competitive in the global markets the bigger firms use their resources and capacities and the small and medium sized companies choose to operate in fields that are relatively less populated by the other firms. The large firms compete on the basis of price due to cheap labor and operational costs. For example many computer software companies have made themselves known in the international markets through the low cost of local engineering services. On the other hand small and medium scale businesses as their target markets, have chosen the markets in industrialized nations that are sensitive to prices and low income markets of the third world countries and by this way they have taken their places in the global markets. For example in Korea, Kia Motors has adopted such a policy. At the same time while expanding the business volume in the international markets they cooperated with Ford Motor Company to prevent additional distribution costs.

The success in the international markets cannot be achieved by only developing an effective strategy. The success depends also on gathering information on the international markets, potential consumers and competitors along with the different and foreign environment. It is necessary to collect this information on a regular basis. It will become easier for companies learn about success and failure as they accumulate experience.

The companies after establishing important operations in many of the foreign markets will direct their efforts to finding new opportunities and growing. The success will change based on the compliance with the local market conditions and meeting the requirements imposed by these conditions. To have a strong position in the global markets it is necessary to benefit from the synergy of the multinational activities outside the national borders. A strong global position can sometimes be established being effective and sometimes by way of a strong competitive power. An important point here is adapting to the changes in the markets and to be ahead of competition by foreseeing such changes. By this way it would be possible to obtain growing opportunities from the markets in the future. The global companies can be faced with different and totally clashing demands. While it is necessary to respond to the demands of the local markets on one hand, on the other it is required to be able to act on a global scale.

\section{II.3.2. Implementation of a Global Strategy Locally}

Today, it is widely accepted that choosing and implementing one or the other of adaptation or standardization alternative that forms the basis for the selection of a strategy in international marketing depends on various conditions. As we know "Situational Approach" in business management and organization is based on the principle of establishing the structure of the organization according to the present situation and the conditions. In this approach it is accepted that instead of the management principles that are valid everywhere and anytime, the principles that change according to the situation and the conditions serve the purpose the best and that the structure of the organization is determined by various internal and external conditions. Different conditions and situations effect the organizational structure and cause the different structures to form [17]. Similarly a global strategy requires different applications under different conditions and in different situations like situational approach. In spite of its very many benefits, in local implementation care must be taken with a global strategy. For example, while Henkel was successfully marketing its product "Pattex" worldwide, the same success was not achieved with its other product "Pritt" [18]. It was determined that this failure had two causes:

- Disregard of Henkel headquarters to the warnings issued by the subsidiaries regarding Pritt based on the research carried out,

\section{- The hastiness of the decisions taken.}

There are a lot of reasons for being unsuccessful in the implementation of a global marketing program [18]. The leading reasons for being unsuccessful can be examined under the following headings, insufficient research, excessive standardization, poor or low quality after sales service, narrow mindedness in program coordination and inflexibility in application. Today most of the firms decide to enter the global markets without running a market test. For example Danish toy company Lego, tried to enter the Japanese market by offering promotional materials like "bonuses" and "gift packages" however they were not as successful in Japan as they were in the United States. It was claimed that the underlying reason for being unsuccessful in this case was assuming that the same strategy would work in two different markets. According to this point of view, what should have been done was to research the Japanese market in detail and determine marketing strategies and tactics that are appropriate for the special conditions of this market. However this route was not chosen and the outcome was not successful. 
As can be seen from the example given above, frequently, the companies cannot use the same marketing program for every market. Along with excessive standardization and local implementation also lack of local experience contributed to the failure of strategies. The lack of sufficient knowledge for and familiarity with the local markets among the top managers located at the headquarters brought along the failure. For example, Polaroid Company followed the same advertising strategy that they implemented in the United States, in Europe with respect to its instant picture camera "Sx-70". At the company headquarters the general idea was such that an instant photography camera would make the consumers happy and that a universal product would yield the same benefits everywhere. However the result was a total failure. To be successful it was required for the company to be oriented in the right direction by the local managers and especially to come up with strategies that are in line with the local needs and demands.

Another subject that care must be taken with is the effect of poor quality after sales service and customer follow up policies on the successful implementation of the global strategies. It is necessary to find fast solutions to local problems. At the same time the distribution system organization must have the necessary and sufficient information pertaining to the product and the strategy.

The narrow mindedness that may show itself during the programming of the global strategies can be overcome with the contributions of the local managers. The local environmental conditions are best known by the local managers. Under the light cast by this knowledge the companies can be made to have longer-term outlooks and strategies. International standardization can turn into a strategy that may prove to be harmful for the company itself. The reason for this is strict and inflexible implementation. However, the results of mandatory adaptations carried out by the companies, without taking into consideration the local trends and the reactions can prove to be unsuccessful.

More accurate decisions can be reached by conducting local market research with respect to the global programs and their success. Another point in support of success is to obtain the necessary support from the local companies. Local discretion and decision making would ensure that the long-range plans are more successful. The problems related with the marketing strategies can be resolved by effective after sales service. In the execution of the global programs there must be sufficient room for flexibility; otherwise programs of standardized nature reduce the competitive power.

Today, the powerful local managers of multinational companies, can no longer bear the decision taken by the center due to the differences in factors of consumers and competition among the countries [19]. The local managers must be able to implement the global programs within the context of the global strategies in accordance with the local demands and needs. For example the same product can be sold under different names in different countries as well as the same named product can be sold with different formulations. Even Coca-Cola may make some changes to its packaging and artificial sweeteners that are used in its formulation in some countries, although it maintains the same name, formulation, and advertisements all over the world. The companies adopting a global marketing strategy must be careful with respect to the below mentioned points when it comes to the implementation of the said policy.

Especially in cases where the research and development activities are directed from the center, it is necessary to obtain the opinions of the regional managers, ask for their points of view and encourage them on this subject. For example, a subsidiary of Unilever in South Africa developed "Impulse" body spray and that product has become a global brand.

For obtaining a global brand the local participation must be ensured with respect to the developments of the marketing programs and strategies. A bottom to top approach will increase the chances of a countrywide implementation and its success. For example, Procter and Gamble recently tested a hygienic pad in different regions and later based on the results obtained, standardized the product, its packaging, positioning and name on a global scale. Along with this, the opinions of the local managers on subjects in the marketing program that are not globally related were asked, and they were also asked how to make the global program better and ways of adapting it to the regions. In the end the idea of distributing samples and coupons came from the local managers. In line with their opinions, the application of distributing coupons and samples was very successful in most of the countries [19].

In the example given above, the contribution of the local managers to the global program was not initially included in the fundamental elements of the global program.

In the example given above, the contribution of the local managers to the global program was not initially included in the fundamental elements of the global program. The local managers must be given the opportunity to control the local budgets in accordance with the local competition and with a view to better meet the needs and demands of the consumers. When the local managers are given the sufficient freedom in the subjects of local operations, industrial relations and government related affairs they concentrate more on these subjects.

It is witnessed that world wide global standardization in goods and services may bring along some dangers with it. During the application of such an 
approach in several markets it is possible to be faced with a lot of difficulties and limitations [20]. It can be said that the assumption that constitutes the basic philosophy of the "global product" concept about the worldwide homogenization of the consumer needs and demands is only valid for some products. It can also be said that there are some market sections in which the inter-country and Intra-country differences increase. Several companies chose global consumer sections as their target markets and be active in these sections with "global product" and "global brand" concepts. Along with the aforementioned companies several other companies are continuing to be operational with activities oriented towards meeting differing needs and demands of each country. Life styles and social differences as well as the regional differences form some market sections. The target markets were limited by the similarity among the consumers and by consumer attitudes. Sometimes by concentrating more on the similarity among the countries instead of the differences make the companies miss some of the local market opportunities.

Similarly, there is no certainty with respect to the compromises made by the consumers in return for lower prices. It is difficult to obtain competitive and cost advantage by keeping the prices low in the international markets. We can further say that the customers that are sensitive to lower prices do not have any brand loyalty. The economic development levels of the countries effect the pricing decisions made in these countries. As an example, the price sensitivity in developing countries is more therefore the product adaptation becomes more effective.

By way of another limitation faced in the application of global standardization, worldwide demand can be created through economies of scale. This situation excludes three important points [20]. Firstly, in flexible production the technological developments prevent the global supply of the outputs. The transportation, distribution, coordination and high management expenses increase the costs. The adaptation of the different preferences among the countries reduces the advantage of the scale economies.

Production costs may not take too much space in the total costs. For example, this is the case in the cosmetics and detergent industries and financial institutions. In these markets the success is related with acting in line with the customer demands rather than the effectiveness of production. It is very important to establish an effective distribution network in the international markets.

In countries where mass communication devices such Television are limited, establishing a network as said will play an important role in the distribution of the consumer goods.

Standardization involves a more product-related approach. However other important elements of the market mix must not also be neglected; and taken into consideration seriously. Furthermore, global standardization strategy may not be appropriate for every product, brand and company; this type of strategy can only be successful under certain conditions. The most important of these conditions can be classified as follows; finding the global market sections, providing potential synergy by way of standardization and having a communication and distribution infrastructure that will reach the target consumers all over the world.

There are several factors limiting the standard strategy development and implementation by the companies. What takes up the first space among these factors is the government placed limitations and trade barriers. The governments can set up barriers by putting into effect tariffs and quotas. The differences in marketing infrastructures in different countries make it difficult to implement the standard strategies. The differences in the conditions of competition among the countries make up another factor that makes the implementation of such a strategy difficult. The local managers must also adopt the standard strategies. The reluctance of the local managers in this subject or the lack of motivation may undermine the effectiveness of the company.

Global standardization can only be chosen for specific products, under certain conditions and as a strategy that is in compliance with the structure and objectives of the company. Along with this, all the elements of the marketing mix in a differentiated strategy will be made to comply with the specific customer needs and environmental factors. In every country business management will apply its own strategy. Between these two end points lies the mixed approach. With mixed approach while some elements of the mixed marketing are applied in a standard way the others are adapted to the local market. This approach can be seen in Figure.1 [20].

As can be seen from the Figure. 1 while all the elements making up the marketing mix in the global standardization strategy are being standardized, in the differentiated strategy all the elements with respect to each country are differentiated. And in mixed strategy that lies between these two end points, the elements that make up the marketing mix are standardized to different extents each and used in their adapted form. For example, Apple Computer Company is selling a world wide standardized product in different countries by utilizing different positioning, impact effect and distribution strategies. Similarly Procter and Gamble is selling a standard product in different countries and regions under adapted impact effort strategies. 


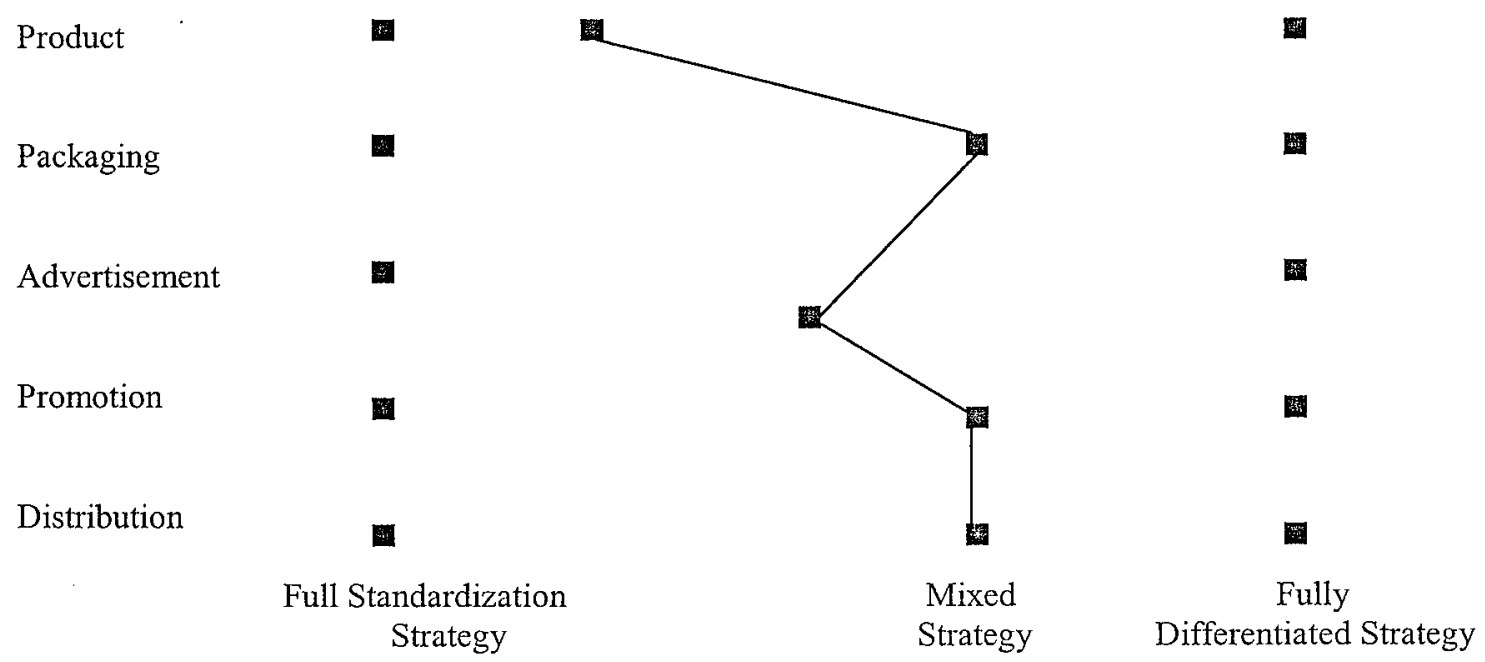

Figure.1 Alternative Approaches in Global Strategy

Source: Douglas, S.P. \& Wind, Y. (1987). The Myth of Globalization. Columbia Journal of World Business, Winter, 27 [11].

In today's world the international trade, competition, consumers, markets and companies are on the way to globalization. The managers while taking decision have the whole world to consider. However due to the differences in cultural, social, and environmental factors among the countries they should make the necessary changes in their marketing plans and their marketing mix elements and implement adaptation [21]. Japanese companies are good examples in this subject. These companies each have their own global strategies; however in compliance with the local demands, customs and environmental conditions they leave the details of the marketing plans and their implementation to their local subsidiaries. This is due to the reason that the local and cultural barriers are making standardization difficult.

\section{II.3.3. The Situational Variables Encountered in the Implementation of the Global Strategy and Their Interaction}

In today's world the marketing strategies are developed under different conditions and variables. The major situational variables that play an important role in the selection of a global strategy can be examined under three main categories [22]. These categories are; product specifications, country specifications and consumer specifications.

Product Specifications. The product can be examined in three groups as a potential for standardization: Fully standard; partially adapted; fully differentiated. Industrial products and advanced technology products are more appropriate for standardization compared to the products that are more sensitive to the cultural norms. On the other hand, durable consumer products form the group that is less sensitive to the effects of culture in the consumer products, in comparison to perishable consumer products. Some products are highly effected from culture therefore in cases as such the demands and the habits of the consumers must be adapted. For example, although dog meat is a food item that is preferred by some nations, it is not a universal product. Due to this reason several restaurants selling dog meat during 1988 Seoul Olympic Games were closed. And sometimes changes like electrical voltage are made in a compulsory manner. Therefore it can be said that without examining the product specifications in depth it would be a mistake to follow a global product strategy. In the end the degree of standardization changes based on the condition and specifications of the product.

Country Specifications. Factors such as the social and political systems of a country, economic and technological development levels, the proportion of readers and writers in the population, cultural homogeneity and similar factors play important roles in the determination of the global strategy to be followed. As an example it is easier to implement the standardization strategy in industrialized societies.

Consumer Specifications. The consumer groups are formed according to various factors like social class, gender, age, place of residence (city or other), and life style. These factors may also help in establishing the international consumer sections. As an example, the purchasing and usage habits of the elite consumer groups are different from such habits of the other groups. Therefore it is a necessity to apply special strategies for this section of consumers rather than a universal strategy [22]. 


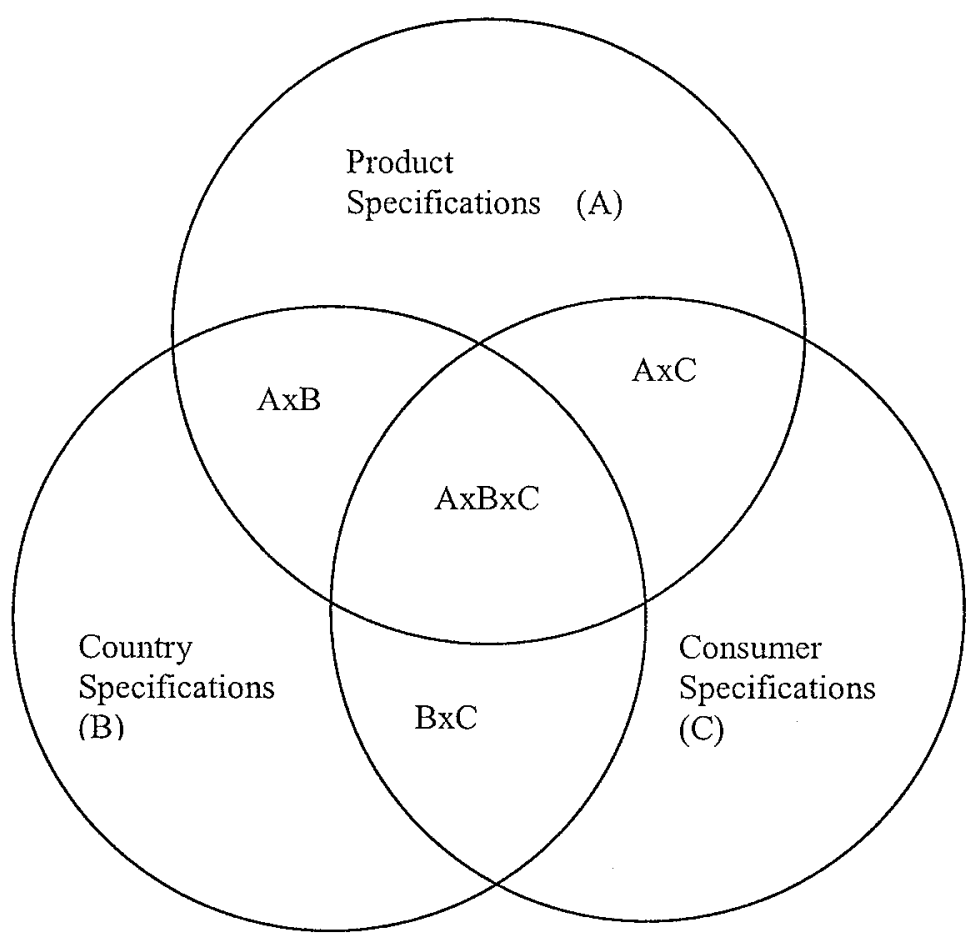

Figure.2 The Interaction of the Situational Variables

Source: Wang, C.L. (1996). The Degree of Standardization: A Contingency Framework for Global Marketing Strategy Development. Journal of Global Marketing, 10(1), 91 [22J.

In the selection and implementation of a successful marketing strategy oriented towards the international markets, the above mentioned groupings based on product, country and consumer specifications along with the situational variables explained above and the interaction of these must be taken into consideration. These variables and the inter-variable interactions play a determining role in establishing the degrees of adaptation and standardization to be applied in the subject matter strategies. In Figure. 2 the interaction of the situational variables is shown. As can be seen from the figure there are areas where these three variables have no interaction whatsoever and there are these areas where the subject matter variables are in interaction in-groups of twos or threes.

In this figure the areas where there is no interaction between the variables are as follows; product specifications (A), country specification (B) and consumer specifications $(C)$. The area where the product and consumer specifications are in interaction can be defined as $\mathrm{AxC}$; the area where the product and country specifications are in interaction can be defined as $A \times B$ and the area where the country and consumer specifications are in interaction can be defined as $\mathrm{BxC}$. Furthermore there is an area where all of the three variables are interacting and that is defined as $\mathrm{AxBxC}$.
After examining the three subject matter variable groups and their interactions the following conclusions were derived [22]:

- If there is no interaction between the three groups of variables, the global standardization strategy can be implemented to take advantage of the international synergy and the economies of scale. The global standardization strategy can be implemented based on the notion that the consumers all over the world have the same needs and demands. In cases as such the consumer are preferring a brand that is universal and that provides universal benefits. In this way, big savings can be realized in the areas of production, distribution, marketing and management.

- If there is an interaction between the product specifications and market sections then marketing mixes according to the global market sections or section can be prepared or different marketing mixes according to different sections can be established. In a case as such, it would be concentrated on international market sections in the global strategy. The concentration will be based on one product instead of several. Standardization in this case can be appropriate for the global consumer sections.

- When there is an interaction between the 
country and the product specifications, product adaptation strategy will be suitable. The specifications pertaining to the country and the product must both be taken into consideration.

- When the country, product and consumer specifications are all in interaction with each other, the international marketing niche strategy can be suitable. The product must be adapted to the country conditions as well as to the conditions of the market sections.

In utilizing the situational approach in international marketing it would prove to be more beneficial to develop a strategy by taking into account the consumer attitudes, consumer specifications and country conditions instead of choosing between the strategies of adaptation or standardization. In this case rather than implementing the "best strategy", "the best strategy based on the conditions and positions" must be developed and implemented. As a matter of fact, today, rather than choosing one of standardization/adaptation strategies as a global marketing strategy, the need to make changes on these strategies based on the specific needs and conditions has surfaced. Although the presence of the global markets is an accepted fact, it is required to choose specific sections in different countries as target markets to be able to compete in these markets.

In choosing the adaptation or the standardization strategy, the elements of the marketing mix, the special conditions of these elements and their qualifications play important roles. Therefore instead of preferring one strategy to the other, different strategies are chosen and implemented under special conditions and in special situations.

Today, global companies use market segmentation to identify, define, understand, and respond to customer wants and needs on a worldwide. Global marketers must determine whether a standardized or adapted marketing mix is required to best serve those wants and needs [23].

The local needs play critical roles in the implementation of the strategic marketing programs. The elements of the strategic program such as distribution makes the adaptation to the local conditions necessary. This approach that is named "glocalization" means "think global, act local". As an example, although Unilever used the same positioning, the same advertising theme and the same symbol (teddy bear) in promoting a laundry softener that was very successful, it used different names, different sizes and amounts of the product in different countries [24].

\section{CONCLUSION}

International marketing has become important concept last twenty years. A lot of forces are driving companies to internationalize via their participation in foreign markets. Chosen strategy is neither standardization nor adaptation, but most often concepts should be customized to local wants and needs.

The businesses form and implement their marketing strategies in the international markets by taking into account the needs of different countries and different consumers. The businesses use the elements of marketing mixes to varying degrees in different strategies. As mentioned above in today's world the companies prefer and implement the "glocalization" strategy more.

\section{REFERENCES}

[1] Jain, S.C. (2001), International Marketing. 6th Ed. Cincinnati, Ohio: South-Western/Thomson Learning.

[2] Jain, S.C. (1989). Standardization of International Marketing Strategy: Some Research Hypotheses. Journal of Marketing, 53(1), January, 70-79.

[3] Terpstra, V. \& Sarathy, R. (1997). International Marketing. $7^{\text {th }}$ Ed. Orlando, FL: The Dryden Press.

[4] Toyne, B. \& Walters, P.G.P. (1993). Global Marketing Management A Strategic Perspective. $2^{\text {nd }}$ Ed. Boston: Allyn and Bacon.

[5] Walsh, L.S. (1993). International Marketing. $3^{\text {rd }}$ Ed. Glasgow: Pitman Publishing.

[6] Usunier, J.C. (1993). International Marketing A Cultural Approach. London: Prentice Hall International.

[7] Shoham, A. (1995). Global Marketing Standardization. Journal of Global Marketing, 9(1/2), 91-119.

[8] Czinkota, M.R. \& Ronkainen, I.A. (2002). International Marketing. Update. Orlando, FL: Harcourt College Publishers.

[9] Baalbaki, I.B. \& Malhotra, N.K. (1993). Marketing Management Bases for International Market Segmentation: An Alternative Look at the Standardization/ Customization Debate. International Marketing Review, $10(1), 19-44$.

[10] Keegan, W.J. (1995). Global Marketing Management. $5^{\text {th }}$ Ed. Englewood Cliffs, New Jersey: Prentice Hall Inc.

[11] Yip, G.S.; Loewe, P.M. \& Yoshino, M.Y. (1998). How to Take Your Company to the Global Market. Columbia Journal of World Business, XXIII(4), Winter, 37-48.

[12] Hout, T.; Porter, M.E. \& Rudden, E. (1982). How Global Companies Win Out. Harvard Business Review, September-October, 98-108.

[13] Hamel, G. \& Prahalad, C.K. (1985). Do You Really Have a Global Strategy. Harvard Business Review, JulyAugust, 139-148. 
Ocak 2006.151-166.

[14] Ghoshal, S. (1987). Global Strategy: An Organizing Framework. Strategic Management Journal, 8(5), 425440.

[15] Ohmae, K. (1989). Managing in a Borderless World. Harvard Business Review, May- June, 152-161.

[16] Craig, C.S. \& Douglas, S. (1996). Developing Strategies for Global Markets: An Evolutionary Perspective. The Columbia Joumal of World Business, Spring, 70-81.

[17] Koçel, T. (2005). Isşletme Yöneticiliğ̈i. 10th Ed. İstanbul: Arıkan Basım Yayım.

[18] Kashani, K. (1989). Beware the Pitfalls of Global Marketing. Harvard Business Review, September- October 1989, 91-98.

[19] Quelch, J.A. \& Hoff, E.J. (1986). Customizing Global Marketing. Harvard Business Review, May-June, 59-68.

[20] Douglas, S.P. \& Wind, Y. (1987). The Myth of Globalization. Columbia Journal of World Business, Winter, 19-29.

[21] Berker, A.T. (1993). A Marketing Oriented Perspective of Standardized Global Marketing. Journal of Global Marketing, 7(2), 123-130.

[22] Wang, C.L. (1996). The Degree of Standardization: A Contingency Framework for Global Marketing Strategy Development. Journal of Global Marketing, 10(1), 89107.

[23] Keegan, W.J. \& Gren, M.C. (2003). Global Marketing. 3rd Ed. Upper Saddle River, N.J: Prentice Hall.

[24] Czinkota, M.R. \& Ronkainen, I.A. (1993). International Marketing. $3^{\text {rd }}$ Ed. Chicago: The Dryden Press.

Gökhan YOLAÇ (sgyol@ttnet.net.tr) has a $\mathrm{Ph}$. D. of International Business at İstanbul University Social Sciences Institute. He is lecturer at Beykent University Social Sciences Institute. His main research areas are marketing communication, brand management, distribution channels and selling management. 